\title{
MEMORIA DE LA DESAPARICIÓN: NOTAS SOBRE POESÍA Y PODER
}

\author{
Antonio MÉNDEZ RuBIO \\ Universitat de València
}

Lo que más sorprende cuando se compara la fase actual con fases precedentes en la historia de estas sociedades es la desaparición casi total del conflicto, sea económico o social, politico o «ideológico».

C. CASTORIADIS

La desaparición tiene memoria. La poesía lo sabe. Ese pulso sin mundo sigue alerta, visible o invisible, audible o inaudible, viviendo de un conflicto no siempre subterráneo. El mundo trabaja para que ese conflicto no le dañe, para que no lo altere como mundo existente. Pero el daño para la poesía no es una opción: es una necesidad. Por eso, la escritura poética tiene la responsabilidad de escuchar aunque fuera el rumor de ese conflicto: abriga el deseo secreto de poder decirlo.

Claro que, entonces, la cuestión del poder, en su sentido más amplio y a la vez más radical, no le es ajena.

$$
* * *
$$

Un título como Poesía y poder, de Alicia Bajo Cero (1997), dice de entrada que el conflicto ha sido detectado, señalado en precario, y a la vez frontalmente. En una entrevista publicada en el otoño de 1980, Gilles Deleuze afirmaba: «Se nos está fabricando un espacio literario completamente reaccionario, prefabricado y asfixiante» (1999: 46). Y este ahogo, esta falta de aire, este «neoconformismo» del que Deleuze hablaba, así como su dimensión ideológica y sociopolítica, era seguramente el principal problema abordado por Alicia Bajo Cero, y el principal lastre que la poesía española acusa marcadamente todavía hoy si se la mira a través de algunos de sus escaparates más deslumbrantes. La poesía, pues, era así 
resituada en el lugar de su práctica, en el espacio de la cultura y la sociedad como campos de fuerza atravesados por diferentes visiones del mundo y diferentes posiciones a la hora de vivir ese mundo de una manera o de otra.

Esta homología entre el espacio literario y el espacio social está siendo intensamente analizada en la última década a propósito de la cuestión del canon. El espacio literario, considerado en sus resortes institucionales, tiende a activar instancias de canonización, y no es extraño: las condiciones de su reproducción dependen de esa actividad. El canon y el poder, el canon del poder y el poder del canon... forman articulaciones heterogéneas y a la vez efectivas, cuyos vínculos con el orden del mundo deberían ser siempre objeto de reflexión para cualquier forma de pensamiento crítico. Se trata, sin duda, de una cuestión compleja, multipolar, que quizá sólo pueda analizarse a partir de aproximaciones parciales y tentativas dialógicas. $Y$ una aproximación de este tipo es lo que creo que suponía el ensayo Poesía y poder -cuya relectura utilizaré sólo como hilo para esbozar preguntas y debates que lo desbordan como texto y que siguen pendientes--. Esta relectura, en las páginas que siguen, no atiende tanto al posible corpus poético figurativo y dominante como a los mecanismos pragmáticos e ideológicos que han contribuido, paulatinamente, a inducir un consenso acrítico e incluso autoritario en torno a ese tipo de poesía.

En gran medida, aún puede decirse que Poesia y poder es hoy un texto desaparecido. Es sorprendente la desproporción entre su presencia en conversaciones informales o privadas y sus fugaces y ambiguos momentos de aparición pública. En el mejor de los casos ha sido considerado un trabajo «imprescindible» (Moga, 2003: 78) o incluso se ha escrito que «es quizá el análisis más metódico, sistemático y desautorizador tanto de la poesía realista como de la crítica que se ha ocupado de ella» (Gracia, 2000: 102). Sólo muy recientemente, con todo, empiezan a tratarse con cierta profundidad los argumentos de Alicia (ver por ejemplo Iravedra, 2002 o Iravedra, 2003), aunque sean éstos tratamientos más abiertos pero todavía orientados a la defensa de una manera canónica de entender el «compromiso».

Sin embargo, con la perspectiva de casi una década, el silencio ha sido la tónica dominante. El colectivo Alicia Bajo Cero, disuelto simultáneamente con la publicación del libro, acogería no obstante ese silencio como una bendición si lo contrastara con las manifestaciones de rechazo que también se han dado. Citaré como muestra sólo dos de estas manifestaciones, curiosamente impresas en medios especialmente relevantes desde el punto de vista de la opinión pública.

La primera aparece en el prestigioso suplemento Babelia, del diario El País («Niebla sobre nieve», 25-1-2003): a propósito de la reseña de un poemario reciente, Poesía y poder se presenta como una serie de «análisis que arrastran un lastre doctrinario que destaca tanto por el esquematismo de su formulación 
como por su radicalidad ideológica». Ahora bien, en el sentido de una propuesta dogmática o cerrada, ¿cuál era la doctrina de Alicia Bajo Cero? El ensayo, según creo, bloquea la respuesta. En cuanto a su esquematismo, puede sin duda que se diera como un límite de la argumentación, pero difícilmente se negará que ese esquematismo se hace eco del esquematismo (este sí, doctrinario) que el ensayo analizaba como su objeto de estudio. Finalmente, en esta secuencia de reproches, uno tiende a asimilar el término «radicalidad» a una descalificación más, cuando quizá se trate justamente de la calificación más indiscutible de todas. La segunda de estas menciones públicas de rechazo apareció en el número 58 de la importante revista Claves de Razón Práctica. La referencia destacaba tanto por su fecha temprana (1995), lo que presuponía un conocimiento de los primeros trabajos de (o de los primeros rumores sobre) Alicia Bajo Cero anteriores al libro, como por la acidez de la actitud. Felipe Benítez Reyes, quien firmaba aquel artículo titulado sintomáticamente «La nueva poesía española: un problema de salud pública», jugaba entre líneas con la identidad agujereada del colectivo para tildarlo de un nuevo «GAL» en el terreno de la poesía contemporánea. Sería costoso en cuanto a tiempo y a espacio entrar a fondo a discutir las premisas de dicha acusación, pero, como mínimo, llama la atención esa ecuación entre disidencia y terrorismo. Sin duda, con casi diez años de perspectiva en los que hemos conocido nada menos que lo que significa la Guerra Permanente contra el Terrorismo, hay que reconocer que con esa ecuación Benítez Reyes demostró ser un adelantado a su tiempo.

\section{Poesía y poder}

Como se sabe, desde principios de los años ochenta del pasado siglo, en el estado español se vivió el cumplimiento de la llamada transición democrática y la llegada al poder político de una socialdemocracia que puso las bases del neoliberalismo actual. Se ha llegado a hablar de los «felices ochenta» para utilizar una expresión que sitúa, por contraste, la depresión colectiva, económica e ideológica, de los noventa, que no por casualidad desembocaron a nivel internacional en la llamada «dictadura de los mercados» así como en nuevos conflictos y movimientos sociales de resistencia ante las políticas económicas, laborales y educativas en curso.

Esta dinámica de retrocesos ideológicos y vitales corrió paralela a la canonización de una poética realista y narrativa, por lo general descreída y conformista, cuyo tradicionalismo formal se escudó en una denominación ambivalente (todo un «bote de humo», por usar el término de Alicia Bajo Cero) y totalizadora: se trataba de la hoy ya célebre poesía de la experiencia. Este rótulo, poesía de la experiencia, no dejaba de ser en parte una construcción arbitraria y resbaladiza, pero eso no le impidió ser reconocida como una convención de identidad, o como 
mínimo de consenso en torno a ciertos principios estéticos e ideológicos comunes (neoclasicismo, individualismo, escepticismo...). Este programa (no necesariamente deliberado) de acción y producción de consenso, como desde el principio indicó Alicia Bajo Cero, se apoyó en los mecanismos tradicionales no ya de la crítica literaria sino de la propaganda, y este mecanismo propagandístico fue lo primero que en más de una ocasión fue denunciado:

Ante el estado de cosas recién pincelado, nos urge reclamar unos irrenunciables presupuestos para el análisis material de la escritura y, más ampliamente, del proceso social. La necesidad de esto se acentúa por cuanto el poder cultural en acto se pretende, precisamente, libre de ideologías y llega a identificar ideología con dogma, ignorando que dicha igualación responde, otro tanto, a una ideología específica, si bien difuminada (Alicia Bajo Cero, 1997: 25).

En coherencia con este planteamiento propagandístico, fue meticulosamente borrada del mapa cualquier alteridad como si, por el mero hecho de serlo, fuera ya per se una alteridad no válida, impertinente, estéril. Por ejemplo, el término tradición, en singular, se usó a menudo como arma arrojadiza contra toda posible diferencia o disidencia. Tradiciones estéticas modernas como el romanticismo o la vanguardia fueron una y otra vez expulsadas de la república. Alicia Bajo Cero se detuvo a documentar ese gesto autoritario, a registrar sus resortes en manos de diversos criticos y publicaciones, desde la conciencia de que se trataba no tanto de un problema radicado en el discurso de uno o varios individuos sino, más bien, además, de una línea de influencia con vocación totalitaria, de un mecanismo de poder, en una palabra.

Como una pieza especialmente relevante de ese mecanismo, es cierto que rápidamente destacaron las posiciones poéticas de Luis García Montero. García Montero supo sintetizar ese ambiente como nadie, aglutinar tendencias en gestación y generalizar lo suficiente en sus ensayos como para convertirse en un referente no exclusivo y quizá ni siquiera central, pero sí fundamental a la hora de entender ese nuevo clima experiencial. De hecho, sus artículos han seguido insistiendo a lo largo de los años en esa posición aglutinadora, de imantación con respecto a la poesía figurativa. (Esta posición pública de García Montero como figura emblemática lo convierte en un referente ineludible de los últimos debates sobre poesía y sociedad, lo que no significa, como no significaba para Alicia Bajo Cero, que el debate se reduzca a su posición pública particular y mucho menos que se trate de una polémica ad hominem -la cual, desde el punto de vista de la crítica social, sería definitivamente improductiva-).

En los textos de García Montero, este poder de imantación era un gesto al tiempo de rechazo de toda huella romántica o vanguardista por cuanto una huella así sólo podría suponer una renuncia purista a la historia concreta y una defensa a ultranza de un sujeto sacralizado y orgulloso de su marginalidad. Había llega- 
do, por fin, la hora de la normalidad en poesía. Como ha dicho el propio García Montero, «más que quemar los libros, deseo volver a ordenar nuestra biblioteca» (2000: 103). Incluso en una frase tan breve (y tan contundente) como ésta se apreciará hasta qué punto la idea de orden (de un orden, una idea de orden fija o convencionalmente asumida) se opone no ya a otras formas de ordenación o articulación sino a la destrucción y la barbarie sin más. Este mismo miedo a lo otro lleva a García Montero a insistir en una defensa prescriptiva de la figuración, puesto que ésta sería la única opción válida «si queremos seguir defendiendo un proyecto de vida en común» (2002: 37). Y así sucesivamente.

Como es lógico, la propaganda cerrada a favor de la «poesía figurativa» implicaba una reescritura de la historia de la poesía española reciente. En relación con las propuestas poéticas de la Generación del 68 o del 70, por ejemplo, donde el desafío de la vanguardia y la crítica del lenguaje habían encontrado una recepción altamente fructífera, se ha insistido en tildar dichas propuestas de «culturalismo excesivo y diversión experimentalista» (García Montero, 2004a: 10), dejando con ello de lado cualquier camino que permita reabrir ese espacio generacional (ese período histórico, en suma) como un espacio de conflicto poético y político (Méndez Rubio, 2004). De todos modos, el caso de la poesía en el período 1968-1978 no deja de ser un caso entre otros, aunque eso sí, un caso cuya consideración obliga a revisar otros casos y aspectos determinantes para entender la poesía y la sociedad españolas del siglo XX. El diagnóstico, en fin, se ha repetido obsesivamente durante las últimas dos décadas, $\mathrm{y}$ sigue repitiéndose todavía hoy sin ninguna reserva:

La normalización de los años ochenta permitió separar la buena poesía realista de la mala, así como poner en duda el prestigio del esteticismo y del experimentalismo vanguardista (García Montero, 2004a: 13).

Esto implica, como se apreciará, que el problema, la amenaza de barbarie no viene sólo de la herencia de las vanguardias sino, al mismo tiempo, de aquella otra poesía figurativa o realista que podríamos llamar no normal, anormal o subnormal, y que García Montero caracteriza acríticamente de manera incontestable: «la mala». Dicho así, sin más, esta afỉrmación ¿da pie a pensar, por ejemplo, que lo malo de la generación del 68 no sería sólo el vanguardismo de Leopoldo María Panero o de José-Miguel Ullán sino también el realismo conflictivo y oscuro de Antonio Martínez Sarrión o Diego Jesús Jiménez, por poner sólo algunos nombres sobre la mesa? Etcétera -ya he dicho que dar nombres o casos es sólo una forma de situar un conflicto más amplio y general-.

¿Polémica entonces? Sí, en el sentido etimológico, aunque no militarista, de la palabra: polemos, lucha, conflicto. ¿Debate? No, debate no, puesto que el debate requiere voluntad de argumentar y pensar en común asumida por todas 
las partes. Sin embargo, y esto (como explicó bien Gramsci mucho antes que Alicia Bajo Cero) es lo que este tipo de discursos comparten con la propaganda como género, las defensas de la «poesía de la experiencia» se han caracterizado sobre todo por una actitud de arrogancia antiteórica y acrítica. El propio García Montero lo ha dicho con acierto irónico: «Más que de una discusión teórica, se trata al final de un estado de ánimo» (2004a: 25). De donde se desprende que de lo que se trata no es de debatir y de pensar juntos sino de animarse, ante todo, a ser, por fin, normales, es decir, por ejemplo, a reconocer el protagonismo que merece a un poeta como Ramón de Campoamor. Así que quien no sea todavía normal no podrá decir, desde luego, que no se le ha explicado qué debe hacer para serlo.

Parafraseando al querido Manuel Vázquez Montalbán, tal vez sería pertinente hoy, y quizá más que nunca, un nuevo Manifiesto subnormal-al menos si lo que se busca es alguna salida o aproximación alternativa a la institucionalización y canonización de la poesía de la experiencia tomada en sus distintas variantes y ramificaciones-. De alguna manera, no obstante, ese contramanifiesto crítico ha sido escrito, pronunciado a múltiples voces, sólo que quizá los micrófonos de la opinión pública no se hayan acercado a ellas lo suficiente. Pienso por ejemplo en un poeta y ensayista como José Viñals, que ha sabido en Huellas dactilares (2001) vincular la escritura de vanguardia a posiciones políticas de izquierda, así como poner a dialogar este pulso crítico y libertario con una «estética de la pobreza». Viñals se ha atrevido, en la teoría y en la práctica, a denunciar el carácter conservador del realismo más convencional, incluso cuando éste se pone al servicio de la denuncia contra el sistema (2001: 62), y a defender el vínculo que une al poeta no ya a su sociedad sino a la necesidad de revolucionarla.

Podrían ponerse más ejemplos, cómo no, pero la cuestión medular seguiría en pie. Esta médula, es decir, aquello que no se ha podido o no se ha querido comprender, en definitiva, se resume en el siguiente pasaje de Miguel Casado:

La vanguardia no es un estilo de época, sino el otro nombre de la escritura poética: un deseo suicida que, ejecutándose siempre, nunca llega a consumarse. $Y$ esta actitud aquí arraiga también en la concepción del mundo (Casado, 2004: 180-181).

Sería, el debate sobre realismo y vanguardia, al menos una ocasión para empezar, para incidir en un espacio que los defensores del canon imaginan esterilizado -a consecuencia de su propio discurso esterilizador--. Del debate no habría por qué esperar, como en un duelo al estilo western, la victoria implacable de unas opciones sobre otras. No, creo que de ese debate, si realmente se diera, podría esperarse como mínimo la apertura dialógica y horizontal de un campo, de un lugar de encuentro y desencuentro, una apertura que, como tal, ya sería poética 
y políticamente antiautoritaria. Y no creo que esto esté en contradicción con la argumentación de Alicia Bajo Cero, al contrario.

Michel Foucault, en diálogo con G. Deleuze, quienes por cierto se desviaron de la normalidad con su escritura y con su vida, abordó con detenimiento la crisis mundana del Sujeto, la Representación, la Claridad... en un mundo, como el nuestro, donde la fractura y el estallido se han vuelto constitutivos del imaginario y del día-a-día. La cuestión del sujeto poético es crucial en este punto. «Deseo suicida» podría significar aquí disolución, entrega a la alteridad, diseminación, esto es, justo lo contrario de solidificación, cristalización o prepotencia orgullosa. Más bien entramos en la órbita de lo que Vladimir Holan entendía por poesía: aquella tarea que te impida enorgullecerte. Dice Foucault (1995: 70):

Más de uno, como yo sin duda, escribe para perder el rostro. No me pregunten quién soy, ni me pidan que permanezca invariable: es una moral de estado civil la que rige nuestra documentación. Que nos deje en paz cuando se trata de escribir.

De Keats a Lautréamont o Mallarmé, la modernidad poética llevaba inscrito este reto, el reto de la desaparición, de la muerte como constituyente de toda vida posible o imposible, del vaciamiento como apertura para respirar. En efecto, por Foucault o por Derrida, entre otros, hemos aprendido que, de hecho,

el ser del lenguaje es la visible desaparición de aquel que habla, esto es, la presencia de una voz manifiesta la ausencia de la conciencia que ha generado esa voz, creemos que el discurso nos significa y nos sitúa ante los demás cuando, en realidad, to que sucede es que nos disolvemos en el instante mismo en que nos manifestamos a través del lenguaje. Mis palabras no prueban sino la desintegración de mi identidad, la disolución de mi propio ser en el ser propio del lenguaje. [...] Y así, después de haberlo escrito, el mundo desaparece en la escritura para ser leído como un texto, el texto del mundo (Saldaña, 2003: 85).

Dicho así, se puede producir la impresión de que el lenguaje poético nos aleja del mundo, se lo quita de en medio, pero esa impresión debería considerar despacio que lo que hace el lenguaje es abrir un espacio (o mejor, un espaciamiento) por donde el sujeto y la realidad pasan «a través»: es decir, que el lenguaje puede entonces ser asumido como una travesía, como un espacio que atravesamos y nos atraviesa, que atraviesa el mundo a la vez que es atravesado por ese mundo, que así puede enseñar no sólo sus contornos sino aquello que esos contornos habían dejado fuera provisionalmente. La realidad, así, más que un espacio previamente delimitado y reconocible es, además, un lugar de desconocimiento y de libertad. Por eso una escritura no realista, no figurativa, puede también ser una escritura emancipadora, crítica y autocrítica, de- y reconstructiva, o si se prefiere «comprometida». 
Hay un ejemplo reciente de esta tensión en el poemario Ciento cuatro días (2003) de Pedro Provencio. El libro de Provencio se construye como un diario impersonal, intermitente, donde el yo no se hace soberano, no se enseñorea de lo que dice sino que se abre a ese decir conciso, de fronteras que quisieran quedar atravesadas por la voz: «Sólo espera que un límite le dé / traslucidez donde perderse pueda». La luz traspasa el cuerpo, lo vuelve un imposible, un acto incumplido donde se cruzan la pérdida y la donación. Como una negación anónima, desbordada por un saber otro, por «el envés del pozo», el sujeto se abre un espacio nuevo, nocturno, para comprender y hablar de otra forma («Ahora que estás perdido...»). Y en esa suspensión, en ese tiempo-ahora reclamado por Benjamin, es entonces justamente accesible la experiencia del salto, de la fractura, del estallido subjetivo y colectivo, como en este poema clave (Provencio, 2003: 135):

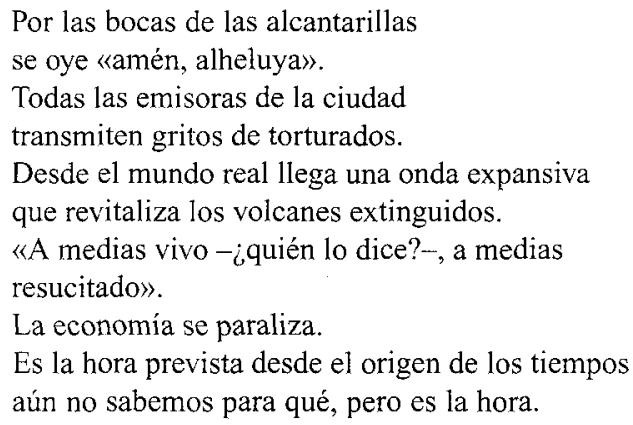

Si la identidad, en fin, entra en una travesía de desaparición (o disolución, pero no simplemente destrucción) entonces cabría esperar que los mecanismos de identificación, de reconocimiento por parte del lector por ejemplo, pasaran a un segundo plano. No se podría sostener ya, sin más, que «el lector acude a la cita para reconocer al otro, y acaba reconociéndose a sí mismo, descubriendo su rostro en el espejo» (García Montero, 2004b: 30). Atacar entonces un poema por sus dificultades de comprensión racional-lineal, como se ha apuntado alguna vez, equivaldría a descalificar Das Kapital porque sólo una minoría lo entendió en su momento. La supuesta transparencia y «deseo de lengua natural» del poema se pondrían así en cuestión, su repliegue en la obviedad sería problematizado por la propia turbiedad de un mundo experimentado como convulsión y revuelta. Este conflicto, cómo no, se cruza en la relación con la lectura, que se ve así interrogada en sus premisas más cómodas y heredadas:

Desde esta perspectiva, en efecto, una poesía donde, en vez de ser cuestionado, el lector puede reconocerse, es menos conflictiva. Los espejos son más efectivos para ello que los interlocutores, sobre todo porque no contradicen, $\mathrm{ni}$ discuten (Talens, en prensa). 
Hasta un realista como Bertolt Brecht era consciente de que el lector, o el espectador, sólo puede acceder a un entendimiento crítico y polémico de lo real a través de un lenguaje distanciado, provocativo, cuestionador. Claro está: Brecht era consciente de esto porque su realismo nunca fue un realismo de proclama sino un realismo experimental, en diálogo permanente con el expresionismo y otras tácticas de vanguardia. Pese a que el paradigma realista subyacía a su trabajo y a su pensamiento de fondo ( «Se trata de las cosas, no de los ojos», le gustaba decir), Brecht no dejó de reclamar desde los años treinta la necesidad de «formular un concepto de realismo más generoso, productivo e inteligente» (Brecht, 1984: 234), un realismo donde dialogaran la concreción y la abstracción, como el que se dio en románticos como P. B. Shelley (a quien Brecht consideraba un «gran realista»). El término pseudorrealismo, que ha sido usado muy recientemente para describir críticamente la lírica aproblemática de la experiencia (Krawietz y León, 2003: 17), fue ya utilizado por Brecht en su ensayo «Amplitud y variedad del estilo realista» (1940). Hablando de los escritores pseudorrealistas del momento explicaba Brecht que

puesto que están dispuestos a todo con tal de obtener la compenetración del lector son sus figuras, del éxito de la cual operación les parece depender todo el valor artístico de su trabajo, comprimen la figura a describir en cada caso hasta que forzosamente tenga que ser posible la compenetración con «cualquier» lector (1984: 264).

Así pues, es coherente con una concepción marxista y materialista del lenguaje y la sociedad apostar por una relación con la lectura y con la realidad en virtud de la cual éstas se vean no simplemente confirmadas según un principio de reconocimiento especular sino, más bien, cuestionadas críticamente, esto es, como decía Valente (1994: 71), atravesadas por «un movimiento de destrucción y reinvención que es a la vez abolición de la realidad y acceso a formas más profundas de ésta». En este camino peligroso, el lenguaje poético no tiene por qué obligarse a representar to real como un a priori, ni por tanto a concebirse a sí mismo como un mero instrumento transparente y estable, una herramienta para la reproducción de una idea obvia de la comunicación. Claro que, desde Platón hasta Breton, esta idea del lenguaje ha recorrido la historia de Occidente con una inercia incontestable, pero esta inercia referencialista y representativa, a su vez, no obliga a entender el lenguaje y la poesía sólo dentro de sus estrechos límites.

\section{Poesía y poder}

De una forma o de otra, la poesía ha de negociar con el poder establecido, sea del tipo que sea, precisamente para poder aparecer. Esto parece de sentido común. La forma más o menos conflictiva de esa negociación tiene algo que decir 
sobre la posición (ideológica y utópica) de esa poesía. Por su parte, el poder también se define en ese roce. En este sentido, del mismo modo que sería idealista creer en una sociedad sin forma alguna de poder que la coordine, y sin embargo esto no conduce por necesidad a la defensa del poder establecido, del mismo modo, insisto, sería idealista confiar en una poesía que absolutice el conflicto y desprecie todo recurso al reconocimiento. Pero esto, en fin, tampoco conduce necesariamente a aceptar como comprometidas las poéticas canónicas que se han normalizado durante los años ochenta y noventa. Parece razonable pensar que la crítica del poder, sea éste del signo que sea, es una necesidad vital de toda democracia, pero lo que seguramente impulsó la intervención de Alicia Bajo Cero fue la impresión de que esa crítica sería difícil y sintomáticamente poco viable. De ahi el (im)propio nombre elegido por el colectivo, un significante giratorio que anticipa la inminencia del estigma.

Es una evidencia a estas alturas indicar que el poder del canon no le es innato o genético a ese canon específico sino que se construye y reconstruye socialmente. En este proceso es asimismo evidente el papel estratégico que juega, entre otros factores, la edición de panoramas y antologías. Un estudio actualizado (Doce, en prensa) ha aportado el dato siguiente: en los últimos veinte años sólo dos antólogos (y poetas), Luis Antonio de Villena y José Luis García Martín, suman entre los dos nada menos que diez antologías de la poesía española actual, es decir, a una media de una antología cada dos años. De ahí que, como denuncia Doce:

Las diez antologías mencionadas, que cubren un abanico temporal de algo más de veinte años, nos han presentado ya, como mínimo, una generación del setenta, otra del ochenta, otra llamada de los «postnovísimos», otra más de «fin de siglo», una generación del noventa y nueve, y finalmente, en 2003 , una última que engloba a los hijos de una cópula entre Razón lógica y Orfeo. [...] Las generaciones ya no se constituyen cada quince años, como sugería en su momento Julián Marías; ahora lo hacen cada quince meses.

El problema, pues, no está tanto en el hecho antológico en sí, una herramienta de difusión por otra parte imprescindible en un marco de cultura masificada, sino en la inercia acrítica que ese hecho supone, incluso más allá de los propósitos del antólogo, cuando el fenómeno se acelera y reitera como lo ha hecho en las últimas dos décadas del siglo XX. En este contexto, en suma, «la antología se emplea sin remilgos como un instrumento de poder destinado a crear una jerarquía o escalafón poéticos que envuelve como melaza el trabajo de las revistas, editoriales e instituciones culturales» (Doce). El etiquetado tiende así a sustituir a la lectura, la inercia al movimiento, la fuerza centrípeta a la del descentramiento... Con todo, el fenómeno de las antologías, insisto, es sólo un ejemplo, un instrumento de poder entre otros, pero un instrumento efectivo que parece proliferar sin remedio. 
A mi entender, si el pensamiento crítico contempla fenómenos como el de las antologías poéticas como puntos de anclaje para una crítica estética y política eficaz debería entonces salvar los riesgos de anecdotismo y entrar en una reflexión más amplia e incisiva sobre el poder como maquinaria no sólo autoritaria sino seductora, no sólo de presencia pública sino invisible. Una aproximación compleja de esta índole está anunciada una y otra vez en los ensayos de Michel Foucault como, para empezar, en su concepción de una «formación discursiva» (como sería en este caso la poesía de la experiencia) como conjunto asubjetivo de reglas que prefiguran la aparición de enunciados, ideas y temas. Foucault fue consciente de que el discurso no es una mera expresión de instancias extradiscursivas ni tampoco un juego meramente intralingüístico, de que, entre las palabras y las cosas, lo real y socialmente vigente no es ni las unas ni las otras sino su cruce práctico y discursivo, ese y que está también agazapado en el título de Alicia Bajo Cero. Las palabras y las cosas, el lenguaje y la realidad, la poesía y el poder... están entrelazados en la práctica, lo que no quiere decir ni, primero, que las cosas o el poder de la realidad agote las potencialidades imaginarias de un poema ni, segundo, que el lenguaje poético se instale en una idealidad absoluta y totalmente autosuficiente. No puede hacerlo porque, a pesar de ser poético, no deja de ser lenguaje, es decir, siguiendo a un marxista como era Voloshinov (1992), una forma de práctica social. Claro que, finalmente, la condición poética le permite a esa práctica conectarse con la realidad no sólo para delimitarla o reafirmarla sino también, como se ha dicho ya, para atravesarla y desbordarla. El realismo más anquilosado puede que sea aquel que entiende esta conexión entre poesía y realidad en clave de subordinación de la primera a la segunda. Las escrituras más conflictivas y revolucionarias puede que sean aquellas que entienden esa conexión a modo de mutua interacción y de mutuo estallido.

En su breve ensayo «El sujeto y el poder» (1995: 165-189) Foucault aborda frontalmente el funcionamiento del poder a partir del gesto crítico que nos ayudaría a pasar del qué al cómo. Dicho más detenidamente: partiendo de la base de que el sujeto humano se inserta en relaciones de poder a la vez que se inserta en una red de relaciones sociales de producción y significación, el punto de partida de un pensamiento crítico efectivo debería entonces empezar por situar la cuestión del poder (del poder literario en nuestro caso) en la textura amplia y compleja de las relaciones sociales e institucionales del momento. Con un acierto limitado, sí creo que Alicia Bajo Cero realizó este esfuerzo, y que ésta puede que sea de hecho su aportación crítica más valiosa y más de raíz. Dichas relaciones no pueden ser sólo de identidad, coherencia o armonía, sino que socialmente, y por descontado en una sociedad en estado crítico como la nuestra, dichas relaciones son también relaciones de tensión y de conflicto. Foucault lo anota en el sentido de que «para comprender en qué consisten las relaciones de poder deberíamos investigar quizá las 
formas de resistencia y los intentos de disociar tales relaciones》 (1995: 168-169). Lo que se cuestiona, pues, como en el caso de Alicia Bajo Cero, es un determinado régime du savoir, un determinado consenso acrítico que vincula de una determinada forma lenguaje y mundo, un acuerdo en fin que se solidifica no por la vía argumentativa y dialógica sino por la fuerza supuestamente incontestable de los hechos. En cualquier caso, así, el poder no es ya estático sino productivo, proyectivo:

El ejercicio del poder no es simplemente una relación entre distintas partes, individuales o colectivas; es una forma en la que ciertas acciones modifican otras. Lo cual equivale a decir, claro está, que ese algo llamado Poder, con o sin mayúscula, que se supone existe universalmente de forma concentrada o difusa, no existe. El poder existe únicamente cuando es puesto en acción, incluso si, desde luego, está integrado a un campo desigual de posibilidades llevadas a actuar sobre estructuras permanentes. Esto significa además que el poder no es una función del consentimiento. No es en sí mismo una renuncia de la libertad, una transferencia de derechos, el poder de todos y de cada uno delegado a unos pocos (lo cual no impide que la posibilidad del consentimiento pueda ser una condición para la existencia y el mantenimiento del poder); la relación de poder puede ser el resultado de un consentimiento previo y permanente, pero no es por naturaleza la manifestación de un consenso (Foucault, 1995: 179-180).

Para Foucault, como se ve, el conocimiento crítico del poder no puede limitarse al hecho de que éste proceda de un consenso específico sino que, más allá, necesitaríamos comprender su aspecto práctico y técnico, el cómo ese poder funciona estratégicamente y provoca o neutraliza conflictos concretos para, en definitiva, alcanzar una comprensión integral (y por tanto potencialmente resistente) de ese poder como mecanismo persuasivo y seductor.

Es significativo que el primer ensayo publicado por el colectivo Alicia Bajo Cero se ocupara de un prólogo (de Luis García Montero a la poesía de Felipe Benítez Reyes). En ese ensayo, que abriría el capítulo Uno de Poesía y poder (1997: 33-51), se denunciaba dicho prólogo como «filtro institucionalizador» mediante el cual se proyectaba el modelo poético «normal» de la poesía de la experiencia «como única propuesta discursiva para la práctica poética contemporánea» (1997: 44). Poesía y poder procuraba así desbloquear la idea en circulación de que dicho prólogo estaba «muy bien tramado teóricamente, y con una solidez que nadie discute» (Lanz, en AA. VV., 1994: 151). En una palabra, se procuraba interrumpir la cristalización de un consenso indiscutible sobre la validez explicativa de una tesis (la tesis de la normalización) que llamaba la atención por su absolutismo teórico y su tradicionalismo estético. De alguna manera, lo que estaba defendiendo este colectivo crítico era, como ha escrito desesperadamente 
Santiago López Petit (1996: 194), que «sólo es posible vivir en la grieta que se abre cuando nos enfrentamos al poder».

Pero «¿cómo criticar un discurso - político, cultural, económico- que se presenta con el lenguaje del no-poder para ejercer mejor el poder? Ésta es la cuestión y la extrema dificultad a la que nos enfrentamos». Con estas palabras (AA. VV., 2004: 28-29) se plantea hoy desde Espai en Blanc, junto con otros colectivos y movimientos antisistémicos, la denuncia de un acontecimiento concreto, el Fòrum de les Cultures de Barcelona. Este acontecimiento se presenta críticamente como una manifestación de «fascismo posmoderno», como nudo en una especie de red de fascismo de baja intensidad cuyas claves operativas serían la inhibición del pensamiento, la legitimación por la pluralidad, la neutralización de lo político y la apología de la realidad como obviedad: «Son las obviedades de lo políticamente correcto. Ante ellas no podemos más que asentir y cerrar la boca» (AA. VV., 2004: 29). Ante la claridad agresiva y autoritaria del canon ideológico (y estético) se insinúa el camino a tientas de una resistencia nocturna (Traful, 2002).

Pues bien, ¿es o no pertinente para el debate el término «fascismo»? También Foucault consideraba el fascismo como

el enemigo mayor, el advesario estratégico. Y no únicamente el fascismo histórico de Hitler y de Mussolini sino además el fascismo que está en todos nosotros, en nuestras cabezas y en nuestros comportamientos cotidianos, el fascismo que nos hace amar el poder. [...] ¿Cómo hacer para no volverse fascista incluso cuando (sobre todo cuando) uno se cree un militante revolucionario? ¿Cómo eliminar el fascismo de nuestros discursos y de nuestros actos, de nuestros corazones y de nuestros placeres? ¿Cómo desalojar el fascismo que se ha incrustado en nuestro comportamiento? (Foucault, 1994: 90).

Siguiendo a Foucault, la salida debe empezar por desplazar toda visión totalizante y por reconocer la fuerza revolucionaria que radica en el vínculo conflictivo entre realidad y deseo. «No os enamoréis del poder», dirá Foucault. El poder, de nuevo. Un poder que se asimila a lo que he llamado un fascismo de baja intensidad en la medida en que se trata de una presión micropolítica, atractiva, neutralizada y naturalizada por la hegemonía de lo obvio, de una supuesta Realidad incontestable. Un poder del que podríamos participar todos-de ahí tal vez su sentido y su vocación totalitaria--

La formación discursiva por excelencia del fascismo, como se sabe, tiene que ver con la proliferación de la propaganda, es decir, justamente con la reproducción de un consenso acrítico, monológico, no argumentativo. Así lo ha analizado sin ir más lejos Adorno aportando una caracterización de la propaganda fascista -que Adorno vivió en su propia carne- a partir de tres rasgos: a) neutralidad antirreflexiva («muy pocos agitadores osarían profesar abiertamente fines fascistas y antidemocráticos», Adorno 2003a: 14); b) clave narcisista de identi- 
ficación y personalización (Adorno, 2003a: 10); y c) sentimentalismo expresivo (Adorno, 2003a: 16). Desde esta perspectiva, nos encontraríamos con un discurso de propaganda fascista cuando «se fetichiza la realidad y las relaciones de poder establecidas, lo cual tiende, más que ninguna otra cosa, a inducir al individuo a entregarse y unirse a la supuesta ola del futuro» (2003a: 19). Se comprenderá así por qué Adorno declara que «quien no se enfrenta a ella se hace literalmente culpable de repetir la política de conciliación» (2003a: 59). La afirmación es más dura de lo que parece, visto que, en el mundo de hoy, hace saltar la pregunta: ¿quién no es en alguna medida cómplice de la política de conciliación y, por tanto, quién podrá eliminar de sí toda huella de una mentalidad fascista? En el terreno de la poesía española que nace de la transición democrática, esta interrogación se volvería acuciante, ya que hablamos de una época marcada por la urgencia de un pacto conciliador como única salida institucional para casi medio siglo de dictadura fascista. No en vano, todavía en el año 2003 podían leerse en la prensa de gran tirada, dentro de la misma página (dedicada al IV Congreso Internacional de la Lengua, El País 13-11-2003), dos declaraciones simultáneas y significativas. La primera pertenece al entonces Secretario de Estado de Cultura: «Hay un momento muy bueno de calidad en la poesía actual que viene de ese diálogo que ya está fuera del dogma». La segunda la firma el columnista que ilustra la noticia: «Hablar de poesía empieza a ser sinónimo de normalidad». Del conflicto y la crítica, al parecer, nunca más se supo.

Quisiera, para acabar con este punto, aclarar lo que supone hablar de un fascismo de baja intensidad en la situación sociopolítica y literaria española del presente. El fascismo aparecería aquí como un elemento explicativo, un componente ideológico (entre otros) que de hecho desbordaría los límites difusos de la poesía de la experiencia como categoría de visibilidad, y que desbordaría asimismo los límites del espacio poético y literario para estar calando en la vida social y política en general. Con razón decía Adorno que no le preocupaban tanto las manifestaciones neofascistas contra la socialdemocracia como los residuos fascistas inherentes a ésta. Fascismo es entonces un mecanismo asubjetivo, diría Foucault, al que los individuos de una democracia (siquiera representativa o formal) tienden a conectarse más por sintonía implícita (dada la genealogía moderna del sistema capitalista) que por identificación explícita (lo que sería insoportable para cualquier forma de opinión pública). Dicho de otra manera, sería un error extraer de aquí la acusación de que «el poeta $X$ o el crítico $Y$ son fascistas». En lugar de una retahíla de acusaciones personalizadas, estoy queriendo sugerir que el fascismo de baja intensidad es en la práctica la descripción de una lógica, de una dinámica ideológica rastreable, según distintos grados de intensidad, en prácticas y en textos concretos. 
Soy consciente de que, hablando de fascismo, se trata de un término singularmente precario, pero no por ello impreciso o inadecuado. Precario porque, en primer lugar, hablamos aquí de poesía, es decir, de un discurso ideológico, desde luego, pero no estrictamente ideológico por definición. En este sentido, son más susceptibles de análisis ideológico los ensayos y manifiestos poéticos que los poemas. En segundo lugar, porque si una ideología de este tipo funciona más por sintonía inconsciente que por identificación abierta entonces, según esto, parece más viable hablar de una proximidad entre cierta forma de poesía y cierta forma de fascismo que hablar de una asimilación total de ésta por aquél. Esta proximidad, no obstante, ¿ayudaría a explicar la poética canónica de una época neo-autoritaria y neo-liberal? La respuesta es díficil, y sin duda debería ser multifacética y matizable. En todo caso, sólo podrá abordarse en toda su complejidad si se contempla lo poético en la encrucijada de lo social, lo económico y lo político en sentido amplio. El conflicto es aquí un conflicto estético e ideológico, vital. Es un conflicto que rara vez asoma en los grandes escaparates de la crítica literaria en boga, pero cuando lo hace lo normal es que aparezca desenfocado. (Un solo y elocuente ejemplo [Doce, en prensa]: Miguel Garcia Posada considera la poesía figurativa como «la mejor poesía que hoy se escribe en España si se juzga con honradez de criterio», Blanco y Negro Cultural 13-9-2003. La cursiva es mía.) Formular el conflicto en términos de «capillas» o de «estados de ánimo»o de descalificaciones meramente personalistas e individuales es sólo un modo, deliberado o no pero eficaz, de neutralizar la dimensión social y política que este conflicto implica. De aplazar para nunca el reto de su comprensión.

\section{Poesía y poder}

Hay una cuestión clave y silenciosa, inquietante, en lo que toca a las relaciones entre poesía y sociedad en una época como la contemporánea. Adorno resumía esta cuestión hablando de «la pérdida de la experiencia a partir de la experiencia de la sociedad» (Adorno, 2003b: 38). La tesis adorniana de la extinción de la experiencia no se orienta hacia una desvinculación de la poesia con respecto a la sociedad sino a una experiencia de la sociedad como catástrofe (que supone a su vez una catástrofe de la experiencia poética y social). Parecerá quizá un detalle demasiado menor, pero no lo es. Lo ha indicado también W. Benjamin en un pasaje célebre de «Experiencia y pobreza» (1990: 168) cuando habla de las gentes que volvían del frente tras la Primera Guerra Mundial:

Las gentes volvían mudas del campo de batalla. No enriquecidas, sino más pobres en cuanto a experiencia comunicable. [...] Una generación que había ido a la escuela en tranvía tirado por caballos, se encontró indefensa en un paisaje en cl que todo menos las nubes había cambiado, y en cuyo centro, en un campo de fuerzas de explosiones y corrientes destructoras, estaba el minimo, quebradizo cuerpo humano. 
La experiencia de la quiebra era así la quiebra de la experiencia. Este derrumbarse del mundo (por cuyos escombros, como quería Benjamin, quizá algún día tracemos caminos nuevos) cle es ajeno al mundo de la miseria y el crimen masivos, al mundo donde las guerras mundiales han sido desplazadas por la mundialización de la guerra permanente? Se diría más bien que en vez de serle ajeno le pertenece históricamente a su raíz.

Por supuesto, en Benjamin o en Adorno, la erosión y la crisis de la «experiencia comunicable» tienen que ver no con una presuntuosa celebración del vacío sino con la dolorosa sacudida de una realidad cada vez más vacía de sentido y al mismo tiempo cada vez más irrenunciable como terreno de juego. Para Adorno, «cuando la literatura en cuanto expresión se convierte en la de la realidad que para ella se desintegra, expresa la negatividad de esa realidad» (2003b: 420). Por esa razón, argumenta Adorno, la escritura poética, creativa, inventiva, conflictiva, sólo puede ser negada por un mundo mercantilista y autoritario. Y por eso la función crítica de la poesía pasa -si no exclusiva sí necesariamente- por la activación de un pulso negativo, una resistencia negativa que no es mera oposición sino, de nuevo, un atravesar (y ser atravesado por) lo real que deja emerger aquello que la realidad niega. Lo que Adorno llama anti-arte (Anti-Kunst) respondería utópicamente a un empobrecimiento que se abre «a lo que no es». Un lenguaje en crisis, como sucede en Beckett, sería un lenguaje no de la prepotencia sino del sufrimiento, la huella negativa de un mundo administrado y colonizado por un poder fundamentalmente intratable. A propósito del realismo más dogmático o convencional, pues, Adorno piensa que éste se ha convertido en una forma de ideología como falsa conciencia (2003b: 420-421):

lo mismo que la mentalidad de las personas llamadas realistas, que se orientan según las instituciones existentes, los deseos y ofrecimientos de éstas, con to cual no se liberan, como ellas se imaginan, de ilusiones, sino que únicamente contribuyen a tejer el velo en el que, como apariencia de ser naturales, la fuerza de las circunstancias los envuelve.

La escritura y el arte que podríamos llamar más «abstractos», «no figurativos» o «de vanguardia», incluyendo ahí los realismos más conflictivos y autocríticos, no son entonces, como se ha dicho a menudo, una simple evasión de la realidad, sino que trabajan por abrir los muros (reconocimiento, obviedad, tradicionalismo...) con que esa realidad se protege a sí misma como realidad existente o establecida.

Desde una mirada abierta como la de Adorno (o la de Benjamin, o la de Brecht...), realismo y vanguardia no se excluyen necesariamente. Es más: pueden ser repensados desde su cruce crítico o negativo. Para eso, sin embargo, necesita repensarse previamente la relación del lenguaje poético con la catástrofe de lo real, con lo real como catástrofe. Y ésta es seguramente la premisa que no com- 
parten los defensores de la poesía canonizada (como poesía de la experiencia) y lo que impide, de fondo, la posibilidad de un debate horizontal y descentrado.

El reto de una escritura negativa, por poner un ejemplo cercano, cristaliza en el poemario Ser no representable (2004), de Víctor M. Díez, donde un sujeo «por su eco hecho añicos» vive en el estallido, en la rotura que hace posible que salga «lo escondido al aire». Así llega a tematizarse esta precariedad de toda ontología en el poema que sigue (Díez, 2004: 31):

Realidades.

Cuerpos que flotan en la charca de la negación.

El calor aún de esos cadáveres. Resistencia que alumbra.

Pequeña bombilla del ser.

No. Insoportables orillas, las arboledas teológicas donde hacen pic-nic las familias de cuerpos secos.

Necesidad de tomar algo para soportar el hedor de su río de corrientes cristalinas y fondos de fango venenoso.

Hay un lugar donde ser luz de luciérnaga, dulce simulacro, verdad a medias.

Antídoto de realidad.

Esta negatividad de resistencia se plantea asimismo en un breve texto de Fermín Herrero (2003: 52):

Siempre a favor de aquello que se niega, de darle la vuelta a la tortilla. Siempre sin sacar nada en limpio. Donde sea imposible.

El poema de Herrero pertenece a El tiempo de los usureros (2003), un título que es ya una denuncia autoconsciente y que insiste lúcidamente en la catástrofe de la experiencia (lenguaje distorsionado, sintaxis en tensión, subjetividad como disolución...) desde una inquietante experiencia del mundo (y la creatividad) como catástrofe. $Y$ de ese desconcierto saltan chispas como la siguiente:

A qué carta quedarse: «Créeme»

de Vicente Feliú o el cuadrado negro

de Malevitch. Seguir en la emoción

$o$ adelantar los signos del desastre. 
El tiempo de los usureros se trama en series paralelas, en contrapunto, lo que refuerza la función táctica del montaje y los procesos (re/de)constructivos que dan lugar a la producción de sentido. Este lugar escindido, dividido, impide la constitución de una unidad fija o una armonía ideal, conduce al lector hacia un momento crítico: allí donde el sujeto, su imposible identidad, se vive como desafío, allí donde la realidad se percibe como necesaria metamorfosis, cuando no como ausencia y como acabamiento. Estas potencialidades conflictivas del montaje paralelo o alterno estaban también activas en un poemario sobrecogedor como El libro de Lilit (1996), de Guadalupe Grande. En el libro de Grande, además, la enunciación se muestra agredida por la condena social inscrita en la diferencia de género, una condena que una subjetividad femenina, dañada, revela.

El recurso a la parataxis, a la dislocación sintáctica y el salto semántico, interviene asimismo en esta pulsión de inestabilidad, de conflicto que busca romper con el orden del discurso para dejar entrever (ver en el entre) sus fisuras, sus puntos de fractura y de vivencia utópica. Por supuesto, los mecanismos de fragmentación colaboran en esta tarea (auto)crítica. La fragmentación, cuya función limítrofe y productiva ha sido certeramente formulada por Eduardo Milán:

Lo inacabado del fragmento tiene un aliento generador, complicante, no en el sentido de complicar lo simple sino de volvernos cómplices de algo. Algo ha acabado allí; se truncó. Pero ¿qué se truncó, por qué no sigue? Y de haber seguido ¿cómo hubiera sido? Se me ocurre que al coletazo de la utopía al que tenemos derecho es al intento de seguimiento, a la imaginación del seguimiento de lo que, aunque provisoriamente, ha concluido. Sería, en este sentido, doblemente utópico: el rastreo de la alternativa, la distorsión, la huella maldita del lado oscuro de lo que ni siquiera fue (Milán, 2004: 41).

Aunque no tengan ni pretendan ningún monopolio simbólico sobre ellos, es demostrable que las huellas contemporáneas de las vanguardias han seguido apostando por el trabajo con estos dispositivos retóricos, con estos efectos de discontinuidad y no clausura, desde una vocación que desde el principio fue tan poética como política -aunque para entender esto haya que reabrir la significación de lo político más acá del estrangulamiento al que lo han sometido sus profesionales. Esa fusión extraña entre arte y vida defendida por las vanguardias y el arte más inconforme al menos desde los años veinte y treinta del siglo XX no podía menos que traducirse en (y verse respaldada por) una experiencia de la escritura y la lectura como extrañamiento, como des-control. Este desconcierto, esta interrogación en los límites de lo visible y lo inteligible, este arremeter contra los límites del lenguaje (Wittgenstein), da pie a Milán para reconocer la vitalidad en poesía de una «tradición libertaria» (Milán, 2004: 126) que ha tendido a quedar desaparecida o invisibilizada por el canon estético e historiográfico oficial. 
Esta tradición libertaria, de resistencia contra el conformismo poético e ideológico se encuentra no sólo en los momentos más álgidos, y quizá más ingenuos de las vanguardias históricas, o en la emergencia expansiva del romanticismo alemán precedente (Sánchez Robayna, 1986) sino que llega viva, a la vez intempestiva y a la intemperie, madura incluso hasta propuestas poéticas actuales. En el contexto de la poesía española, sin ir más lejos, da muestras entre otras de esta encarnación material la obra de Olvido García Valdés. Habría que mencionar por fuerza la publicación del poemario de García Valdés titulado Del ojo al hueso (2001), donde la latencia de lo inacabado y la investigación sobre el fragmento le subyace al temblar. La frágil inminencia de la alteridad deja entonces al descubierto la posición de la subjetividad, entregada a ese rumor nocturno: «fulgor de los espinos y el musgo, casa / no hay para nadie, en los bosques / moramos» (2001: 75). Por esta senda inconclusa y de intemperie el lenguaje no tiene más remedio que volverse problemático, autorreflexivo, al tiempo que, en virtud justamente de ese vértigo dulce, se asoma al agujero negro del deseo, de lo no transparente, de lo oculto o, mejoŕ, de lo que está tan sólo agazapado (García Valdés, 2001: 74):

En el pulso el temblor cuando comienza marzo y duda del referente de algunas palabras, de amigos, por ejemplo. De su referente en lo real, de la necesidad de referentes, de lo real de los referentes (y la frase transmitida: oh amigos, no hay ningún amigo). Qué suerte entonces nuestro cuerpo de pocitos oscuros.

La poesía de García Valdés, como otras poéticas que podrían y deberían ser convocadas aquí, es ejemplar para comprender mejor cómo crisis y crítica mantienen en la escritura un vínculo no sólo etimológico. Si ese vínculo recorre y traspasa las palabras, el lenguaje, entonces parece razonable hablar de conflicto y de crítica social - otra cosa distinta es que esa crítica no sea explícita ni deliberada-. Desde el punto de vista formal (y material por tanto) se da en escrituras no figurativas y vulnerables como éstas más de una de las premisas que Castoriadis (2000) pedía a toda «exigencia revolucionaria», esto es, principalmente, la abnegación y la pasión de entrega, de una parte, y la apertura y el agujereado de lo real y el lenguaje, de otra.

Llegados a este punto, en fin, espero haber esbozado sintéticamente por qué la poesía experimental, de vanguardia o abstracta, no figurativa, o como se la quiera llamar para así delimitar semánticamente aquello que radica en la provocación de los límites, pues bien, haber esbozado por qué este tipo de propuestas poéticas no canónicas pueden estar cumpliendo una labor imperceptible, invisible 
si se quiere, pero materialmente incisiva a la hora de testimoniar y dejar huellas del desastre del mundo ya a la entrada del siglo XXI.

Vista así, la cuestión estaría planteada de forma incorrecta si se postula por ejemplo que (este camino frente al capitalismo, representado en la teoría estética de Adorno, implica finalmente la renuncia a la historia, el abandono de cualquier espacio público» (García Montero, 2000: 88). Pienso por el contrario que este camino frente al capitalismo y la miseria de un mundo del que el poeta forma también parte como un sujeto social que es al fin y al cabo, este camino doloroso y a tientas, en suma, más que renunciar a la historia está procurando desvelar las zonas de lo real que esa historia ha ido dejando desaparecidas -empezando por las zonas libres en el lenguaje y la percepción del mundo que nos permitirían reconstruirlo de otra forma en la práctica cotidiana, subjetiva y colectiva-. El espacio público no puede abandonarse al tiempo que se realiza un acto cualquiera de lenguaje (un poema, en este caso) puesto que todo lenguaje es, en acto o en potencia, social, un territorio común, como diría el desaparecido Voloshinov. Más bien podría decirse que lo que aquí está en cuestión es la experiencia de lo público como experiencia de ausencia y de vacío. El recurso al fragmento y a lo inacabado, como ditía tal vez Adorno, atestiguan la catástrofe histórica que ese vaciado supone, a la vez que abren el discurso poético para la intervención -no especular sino crítica y autocrítica- de un lector que la publicidad masiva y la propaganda institucional conciben en clave de pasividad y desmemoria.

La acusación vertida contra las vanguardias (así, en general) por su supuesto orgullo, su marginalidad autoexcluyente o su «rebeldía solipsista» tal vez se haya emitido sin tener en cuenta que el solipsismo, por sentido común, puede estar en el texto y/o en los ojos que lo leen. Ayudaría asimismo considerar que la crisis y la crítica del sentido, en todo caso, intervienen de distinta forma cuando responden a un gesto no de autosuficiencia sino de insuficiencia, no de prepotencia sino de precariedad ante un mundo donde la linealidad aproblemática de una «experiencia comunicable», siguiendo a Benjamin, tiene mucho que ver con una posición de indiferencia y de ensimismamiento.

En este punto entró en la discusión, precisamente para activarla y no para paralizarla, el trabajo analítico de Alicia Bajo Cero. Pese a lo que alguna vez se ha escrito (Iravedra, 2003) no hay en el texto de Poesía y poder ninguna apología de la marginalidad, que desde luego es una posición dependiente de la lógica del centro y del poder, sin duda. Por lo visto, puede resultar chocante que alguien, como este colectivo desaparecido, pueda reconocerse marxista y oponerse a las tesis de otro alguien que también se reconoce a sí mismo como tal, como es el caso de García Montero. Pero no parece chocante en la misma medida, por poner sólo un ejemplo una vez más, que García Montero se oponga a un marxista heterodoxo y de mayor capacidad reflexiva que cualquiera de los citados, como sería el caso de 
Theodor W. Adorno. Adorno, por su parte, se atrevió a pensar el régimen de relaciones entre la ratio ilustrada y el fascismo contemporáneo en un libro fascinante, Dialéctica del iluminismo (2003), que escribió con Max Horkheimer. Y tampoco parece interesar demasiado la oportunidad de contrastar pasajes concretos de Adorno y de Garcia Montero para comprobar que hay en juego opiniones respetables pero equivocadas ya desde sus puntos de partida. Se dice, en pocas palabras, «las vanguardias son asociales» y no se aclara si es asocial Neruda, Ory, Ungaretti, García Lorca, Brecht, Huidobro, Tzara... o si lo son todos a la vez. ¿Qué significa social cuando se dice esto? ¿Se debería decir mejor institucional o convencional, en el sentido de acuerdo tácito con determinadas regulaciones normativas? Si así fuera, sin duda, podríamos ponernos de acuerdo en que estos nombres remiten a un distanciamiento con respecto a las normas estéticas e ideológicas de su tiempo. Un romanticismo que anuncia las vanguardias en su época tardía, como el de Hölderlin, ¿en qué medida se autoexcluye? Podría decirse, creo, que en efecto habría «autoexclusión», si se quiere decir así, por cuanto hay en Hölderlin una distancia asumida con respecto a las convenciones asfixiantes de aquella sociedad en declive. Pero no hay «autoexclusión», ni puede haberla en sentido estricto, cuando ese distanciamiento de la mirada y la palabra se transforma en testimonio de un mundo y un orden opresivos. Más bien al contrario, lo que habría entonces sería una denuncia ( $y$ hay que insistir: no necesariamente explícita o temática) de una realidad excluyente y autoritariamente normalizadora.

Precisamente en un contexto de movilización antiautoritaria y de acción social crítica es donde nace y se disuelve finalmente la propuesta de Alicia Bajo Cero. De hecho, Poesía y poder se edita en una colección que previamente había ya sacado a la luz tres títulos colectivos sintomáticos: Textos por la insumisión (1992), El lugar del reencuentro (1995) y La mirada urgente (Textos contra el racismo) (1995). Como se explicaba en el propio prólogo de Poesía y poder, titulado «Cultura y revolución», esos tres textos nacieron de la interacción entre la Unión de Escritores del País Valenciano (disuelta con posterioridad en el seno del Foro Social de las Artes) y, respectivamente, el Movimiento de Objeción de Conciencia, las Madres de Plaza de Mayo y Valencia Acoge. Pero este dato no ha parecido relevante para los escasos y a menudo irritables exegetas del ensayo de Alicia. Si este colectivo, en la práctica, defendía a la vez la formación de redes de movilización y crítica social y la recuperación del «compromiso» poético no necesariamente figurativo, ¿estaba entonces oponiéndose a todo vínculo social o (mejor sería decir) al vínculo institucional -es decir, a la forma propia que tiene el poder establecido de entender lo social-? ¿Se trataría sencillamente de un simple caso de esquizofrenia -opción no descartable en una época agudamente contradictoria de capitalismo tardío como la nuestra-? ¿O había en la posición de Alicia Bajo Cero una coherencia que se ha visto, sin embargo, por unas u otras razones, desaparecida? 


\section{BIBLIOGRAFÍA}

AA. VV., Últimos veinte años de poesía española, Oviedo, Ayuntamiento de Oviedo, 1994.

- La otra cara del Fòrum de les Cultures S. A., Barcelona, Edicions Bellaterra, 200.4.

Adorno, Theodor W., Discurso, poder y subjetividad, Buenos Aires, El Cielo por Asalto, 1995.

- «Poética, política, ideología», Ínsula, 671-672 (2002), pp. 19-20, 37.

- Ensayos sobre la propaganda fascista, Barcelona, Voces y Culturas, 2003a.

- Notas sobre literatura, Madrid, Akal, 2003b.

- «La poesía de la experiencia», en L. García Montero, Poemas, Madrid, Visor, 2004a, pp. 9-25.

- «Las primeras palabras», en L. García Montero, Poemas, Madrid, Visor, 2004b, pp. 27- 34.

Adorno, Theodor W. y M. HORKHEIMER, Dialéctica del iluminismo, Madrid, Trotta, 2003.

Alicia Ba.jo Cero, Poesia y poder, Valencia, EBC, 1997.

BENITEZ REYES, Felipe, «La nueva poesía española: Un problema de salud pública», Claves de Razón Práctica, 58 (1995), pp. 52-55.

Benjamin, Walter, Discursos interrumpidos I, Madrid, Taurus, 1990.

BRECHT, Bertolt, El compromiso en literatura y arte, Barcelona, Península, 1984.

Casado, Miguel, Archivos (Lecturas 1988-2003), Burgos, Editorial Dossoles, 2004.

CASTORIADIS, Cornelius, La exigencia revolucionaria, Madrid, Acuarela Libros, 2000.

Deleuze, Gilles, Conversaciones, Valencia, Pre-Textos, 1999.

DiEz, Víctor M., Ser no representable. Mérida, De la Luna Libros, 2004.

DOCE, Jordi, «Poesía española de hoy: de la arbitrariedad a la domesticación», en A. Sánchez Robayna y J. Doce (eds.), Poesia hispánica contemporánea, Barcelona, Galaxia Gutenberg / Círculo de Lectores, en prensa.

FOUCAULT, Michel, «El antiedipo: una introducción a la vida no fascista», Archipiélago, 17 (1994), pp. 88-91.

- Discurso, poder y subjetividad, Buenos Aires, El Cielo por Asalto, 1995.

García MonTero, Luis, «El oficio como ética», en J. Romera Castillo / F. Gutiérrez Carbajo (eds.), Poesía histórica y (auto)biográfica 1975-1999, Madrid, Visor, 2000, pp. 87-103.

- «Poética, política, ideología», Ínsula, 671-672 (2002), pp. 19-20, 37.

- «La poesía de la experiencia», en L. García Montero, Poemas, Madrid, Visor, 2004a, pp. 9-25. 
- «Las primeras palabras», en L. García Montero, Poemas, Madrid, Visor, $2004 \mathrm{~b}, \mathrm{pp}, 27-34$.

García Valdés, Olvido, Del ojo al hueso, Madrid, Ave del Paraíso, 2001.

GRACIA, Jordi, «La poesía», en F. Rico (ed.), Historia y crítica de la literatura española 9/I, Barcelona, Crítica, 2000, pp. 97-121.

GrANDE, Guadalupe, El libro de Lilit, Sevilla, Renacimiento, 1996.

Herrero, Fermín, El tiempo de los usureros. Madrid, Hiparión, 2003.

IRAVEDRA, Araceli, «¿Hacia una poesía útil? Versiones del compromiso para el nuevo milenio», Insula, 671-672 (2002), pp. 2-8.

- «Radicales, marginales y heterodoxos en la última poesía española (contra la "poesía de la experiencia")», comunicación al II Congreso Internacional Orbis Tertius de Teoría y Crítica Literaria, Buenos Aires, Universidad Nacional de la Plata, 2003.

KRAWIETZ, Alejandro y Francisco LEÓN, La otra joven poesía española, Tarragona, Ígitur, 2003.

López Petit, Santiago, Horror vacui (La travesia de la Noche del Siglo), Madrid, Siglo XXI, 1996.

MÉndez Rubio, Antonio, Poesia '68 (Para una historia imposible: Escritura y sociedad 1968-1978), Madrid, Biblioteca Nueva, 2004.

MILÁN, Eduardo, Resistir (Insistencias sobre el presente poético), México, FCE, 2004.

Moga, Eduardo, «Los noventa: lo otro», Contrastes, 27 (2003), pp. 77-80.

Provencio, Pedro, Ciento cuatro dias, Valencia, Germanía, 2003.

SAldaña, Alfredo, El texto del mundo (Critica de la imaginación literaria), Zaragoza, Anexos de Tropelías, 2003.

SÁnCHeZ RoBAYNA, Andrés, «La modernidad literaria: una literatura de las excepciones», Syntaxis, 10 (1986), pp. 29-34.

TALENS, Jenaro, «Contrapolíticas del realismo (De ética, estética y política)», en A. Sánchez Robayna y J. Doce (eds.), Poesia hispánica contemporánea, Barcelona, Galaxia Gutenberg / Círculo de Lectores, en prensa.

TRAful, Mar, Por una política nocturna, Madrid, Debate, 2002.

VAlente, José Ángel, Las palabras de la tribu, Barcelona, Tusquets, 1994.

VIÑALS, José, Huellas dactilares, Barcelona, Montesinos, 2001.

VoloshrNOV, Valentin N., El marxismo y la filosofia del lenguaje, Madrid, Alianza, 1992. 